\title{
Joint of the Pelvic Girdle
}

National Cancer Institute

\section{Source}

National Cancer Institute. Joint of the Pelvic Girdle. NCI Thesaurus. Code C32890.

Any of the joints within the pelvic girdle. 